\title{
Geochemical and environmental magnetic characteristics of high arsenic aquifer sediments from Datong Basin, northern China
}

\author{
Xianjun Xie · Yanxin Wang · Mengyu Duan •
}

Zuoming Xie

Published online: 26 August 2008

(C) Springer-Verlag 2008

\section{Erratum to: Environ Geol}

\section{DOI 10.1007/s00254-008-1489-4}

The original version of this article unfortunately contained mistakes.

The corrections are given below:

The corresponding author of this manuscript is Dr. Yanxin Wang.

In abstract, line 12: $r=0.11$ must change to $r^{2}=0.11$.

The online version of the original article can be found under doi:10.1007/s00254-008-1489-4. 